\title{
Ciência, política, história e os intrigantes e persistentes mistérios das pandemias
}

Estamos no curso de mais uma pandemia (Covid-19) relacionada a um novo agente etiológico, o coronavírus SARS-COV-2, o qual, apesar de sua alta transmissibilidade, tem uma relativamente baixa patogenicidade. Apesar da turbulência que vem causando nos sistemas de saúde, os seus efeitos sobre a saúde podem ser considerados de média intensidade, quando comparados com os efeitos mais letais de outras pandemias no passado ou com possíveis epidemias no futuro. Com estas características, até final do mês de agosto de 2020 já havia atingido mais de 23 milhões de pessoas e dizimado mais de 800 mil destas. Seus efeitos têm sido impactantes não somente na saúde (física e mental), mas também sobre a economia e a vida social, em geral. Para sua solução, uma grande responsabilidade tem sido colocada sobre a ciência. Os pesquisadores têm buscado responder estas expectativas, tentando entender, em tempo real, a pandemia, seu agente, seus efeitos e, principalmente, buscar ou desenvolver soluções. Até o momento, temos uma imensa quantidade de material científico produzido. Somente o Pubmed registrava aproximadamente 45 mil documentos científicos publicados, crescendo a uma velocidade de 2.000 por semana. Alguns pequenos avanços são registrados na área dos medicamentos, ainda que esta seja uma área promissora. Na prevenção, entende-se a importância do distanciamento físico e do uso de máscaras, e a corrida por uma vacina está lançada, esperando-se, por enquanto sem certezas, de que nela esteja a solução para a Covid-19.

Em outro front, os políticos movimentam-se intensamente para viabilizar (ou não) a medida mais efetiva que temos até o momento para o controle da pandemia - o distanciamento físico. Os melhores resultados são observados entre aqueles que conseguem mobilizar as capacidades existentes através de uma liderança política efetiva. Governos que de forma eficiente coordenaram a ação política e que se utilizam do conhecimento científico acumulado, parecem ter tido maior sucesso na contenção da epidemia. Porém, e ao mesmo tempo, em muitas nações, as políticas neoliberais os têm arrastado para a austeridade fiscal, com redução dos investimentos públicos em pesquisa e desenvolvimento e nos sistemas de saúde.

Não há dúvida de que a ciência atingiu um alto patamar de desenvolvimento e vem conseguindo apresentar contribuições para desvendar elementos da pandemia. Por exemplo, na grande pandemia anterior, a Gripe Espanhola de 1918-1911, o distanciamento físico e o uso de máscaras foram preconizados. No entanto, diferente de agora, não existiam instrumentos para mensurar e avaliar a efetividade de sua adoção. Contudo, nos últimos anos, em paralelo com o desenvolvimento das ciências e do conhecimento científico, cresce o movimento de negacionismo deste mesmo conhecimento. Avanços científicos incontestes e que trouxeram imenso impacto na saúde das populações, como as vacinas, são renegados, a ponto de pôr em risco o estágio de controle de doenças, como o sarampo! Os medicamentos, cuja eficácia sempre foram atestadas por pesquisadores, após laboriosos testes são, agora, de maneira surpreendente, definidas por estes mesmos negacionistas, com frequência, em posições políticas de grande relevância.

Tudo isto vem acontecendo com surpreendente rapidez e nos trazendo imensas perplexidades ${ }^{2}$. Como, no decorrer do século XXI, podemos ainda presenciar uma devastadora pandemia dotados de limitados recursos para controlá-la? Como ver parte do esforço científico ser solapado por uma influente convergência da direita política com o negacionismo científico? Não existem dúvidas de que estas e muitas outras questões estarão no centro dos debates científicos e políticos pelos próximos meses, anos e talvez décadas. Porém, para nós pesquisadores da área da saúde, no sentido de contribuir para o enquadramento das nossas investigações, faz-se relevante pontuar alguns aspectos que têm sido recuperados pela estimulante historiografia sobre as pandemias, as epidemias e as doenças infecciosas, em geral:

1. O declínio das doenças infecciosas, iniciada no final do século XIX, e as tecnologias para o seu tratamento e controle desenvolvidas no século XX, motivaram a 'crença' de que elas iriam desaparecer. No entanto, em grande parte consequência das intervenções humanas no ambiente natural e social, elas não somente reemergem ao final do século, como revigoram o seu potencial pandêmico ${ }^{3}$. 
Mauricio L. Barreto (https://orcid.org/0000-0002-0215-4930) ${ }^{1}$

${ }^{1}$ Centro de Integração de Dados e Conhecimentos para Saúde, Fiocruz. Salvador BA Brasil.

\section{Referências}

1. Barry JM. The Great Influenza: The Epic Story of the Deadliest Plague in History. New York: Viking; 2004

2. Rodhain F, Saluzzo JF. Grippe, rage, méningite, sras... le mystère des épidémies. Paris: Éd. Pasteur; 2005.

3. Institute of Medicine. Emerging infections: microbial threats to health in the United States. Washington: National Academy Press; 1992.

4. McNeill WH. Plagues and peoples. New York: Doubleday; 1977.

5. Ranger T, Slack P, editors. Epidemics and ideas: essays on the historical perception of pestilences. Cambridge: Cambridge University Press; 1995

6. Baldwin P. Contagion and the state in Europe 1830-1930. Cambridge: Cambridge University Press; 1999.

7. Watts S. Epidemics and history: disease, power and imperialism. New Haven: Yale University Press; 1997

8. Evans RJ. Death in Hamburg: Society and politics in the cholera years 1830-1910. Oxford: Clarendon Press; 1987

9. Barreto ML. Health inequalities: a global perspective. Cien Saude Colet 2017; 22(7):2097-2108

10. Watts N, Adger WN, Ayeb-Karlsson S, Bai Y, Byass P, Campbell-Lendrum D, Colbourn T, Cox P, Davies M, Depledge M, Depoux A, Dominguez-Salas P, Drummond P, Ekins P, Flahault A, Grace D, Graham H, Haines A, Hamilton I, Johnson A, Kelman I, Kovats S, Liang L, Lott M, Lowe R, Luo Y, Mace G, Maslin M, Morrissey K, Murray K, Neville T, Nilsson M, Oreszczyn T, Parthemore C, Pencheon D, Robinson E, Schütte S, Shumake-Guillemot J, Vineis P, Wilkinson P, Wheeler N, Xu B, Yang J, Yin Y, Yu C, Gong P, Montgomery H, Costello A. The Lancet Countdown: tracking progress on health and climate change. Lancet 2017; 389(10074):1151-1164.

11. Specter M. Denialism: How irrational thinking harms the Planet and threatens our lives. New York: Penguim Press; 2009. 